\title{
Bioavailability of the flavonol quercetin in neonatal calves after oral administration of quercetin aglycone or rutin
}

\author{
J. Maciej, ${ }^{*}$ C. T. Schäff, ${ }^{*}$ E. Kanitz,† A. Tuchscherer,‡ R. M. Bruckmaier,§ S. Wolffram,\# and H. M. Hammon* \\ *Institute of Nutritional Physiology "Oskar Kellner," \\ †Institute of Behavioural Physiology, and \\ †Institute of Genetics and Biometry, Leibniz Institute for Farm Animal Biology (FBN), Wilhelm-Stahl-Allee 2, 18196 Dummerstorf, Germany \\ §Veterinary Physiology, Vetsuisse Faculty, University of Bern, 3001 Bern, Switzerland \\ \#Institute of Animal Nutrition and Physiology, Christian Albrechts University Kiel, 24118 Kiel, Germany
}

\begin{abstract}
Polyphenols, such as flavonoids, are secondary plant metabolites with potentially health-promoting properties. In newborn calves flavonoids may improve health status, but little is known about the systemically availability of flavonoids in calves to exert biological effects. The aim of this study was to investigate the oral bioavailability of the flavonol quercetin, applied either as quercetin aglycone (QA) or as its glucorhamnoside rutin (RU), in newborn dairy calves. Twenty-one male newborn German Holstein calves were fed equal amounts of colostrum and milk replacer according to body weight. On d 2 and 29 of life, $9 \mathrm{mg}$ of quercetin equivalents $/ \mathrm{kg}$ of body weight, either fed as QA or as $\mathrm{RU}$, or no quercetin (control group) were fed together with the morning meal. Blood samples were taken before and $0.5,1,1.5,2,2.5,3,4,5,6,12,24$, and 48 $\mathrm{h}$ after feed intake. Quercetin and quercetin metabolites with an intact flavonol structure (isorhamnetin, tamarixetin, and kaempferol) were analyzed in blood plasma after treatment with glucuronidase or sulfatase by HPLC with fluorescence detection. Maximum individual plasma concentration was depicted from the concentration-time-curve on d 2 and 29, respectively. Additional blood samples were taken to measure basal plasma concentrations of total protein, albumin, urea, and lactate as well as pre- and postprandial plasma concentrations of glucose, nonesterified fatty acids, insulin, and cortisol. Plasma concentrations of quercetin and its metabolites were significantly higher on $\mathrm{d} 2$ than on d 29 of life, and administration of QA resulted in higher plasma concentrations of quercetin and its metabolites than RU. The relative bioavailability of total flavonols (sum of quercetin and its metabolites isorhamnetin, tamarixetin, and kaempferol) from RU was $72.5 \%$ on d 2 and $49.6 \%$ on d 29 when compared
\end{abstract}

Received January 20, 2015.

Accepted February 6, 2015.

${ }^{1}$ Corresponding author: hammon@fbn-dummerstorf.de with QA (100\%). Calves fed QA reached maximum plasma concentrations of total flavonols much earlier than did RU-fed calves. Plasma metabolites and hormones were barely affected by QA and RU feeding in this experiment. Taken together, orally administrated QA resulted in a greater bioavailability of quercetin than RU on d 2 and 29, respectively, and quercetin bioavailability of quercetin and its metabolites differed markedly between calves aged 2 and $29 \mathrm{~d}$.

Key words: bioavailability, calf, flavonoid, quercetin, rutin

\section{INTRODUCTION}

Flavonoids are secondary plant metabolites occurring ubiquitously in all higher plants (Manach et al., 2004; Besle et al., 2010). They are known for their health-promoting properties (e.g., antioxidative and anti-inflammatory; Middleton et al., 2000; Nijveldt et al., 2001; Williams et al., 2004). Quercetin is one of the most abundant flavonoids and is present in high concentrations in onions, apples, and kale (Hertog et al., 1992; Nijveldt et al., 2001), and in low concentrations in milk (Besle et al., 2010; Bhagwat et al., 2013). In addition to their health-promoting properties, quercetin and its metabolites modulate the expression and activity of several metabolic key enzymes, and therefore might be involved in regulation of lipid and carbohydrate metabolism (Middleton et al., 2000; Gasparin et al., 2003; Kobayashi et al., 2010).

Newborn calves undergo tremendous immunological and metabolic changes after birth to adapt for extrauterine life (Blum, 2006; Chase et al., 2008; Hammon et al., 2012) and colostrum management is one of the most important factors to support neonatal health and development (Godden, 2008; Hammon et al., 2012). Nevertheless, morbidity and mortality rates are still high during first weeks of life, and calves often suffer from diarrhea and respiratory disease (McGuirk, 2008; Mee, 2008; Uetake, 2013) as well as high levels of oxidative stress (Inanami et al., 1999; Gaál et al., 
2006). Frequent problems on farms are the lack of high-quality colostrum availability and the insufficient colostrum supply (Quigley and Drewry, 1998; Godden, 2008). Colostrum and mature milk contain antioxidant agents to protect neonatal calves from oxidative stress (Lindmark-Månsson and Åkesson, 2000; Besle et al., 2010). Poor quality of colostrum is reflected by low concentrations of antioxidative substances. Thus, supplementing colostrum and milk at the beginning of lactation with the natural antioxidant agent quercetin may improve neonatal oxidative status. However, there is no information about the bioavailability (BV) of orally applied quercetin with colostrum and milk in newborn calves, although feeding industry already offers flavonoid-supplemented feed for dairy calves.

Studies on BV of quercetin from quercetin aglycone (QA) or its glucorhamnoside rutin (RU) in different monogastric species, such as rats (Manach et al., 1997), pigs (Ader et al., 2000; Cermak et al., 2003; Lesser et al., 2004), dogs (Reinboth et al., 2010), and humans (Erlund et al., 2000; Egert et al., 2008), showed marked differences to ruminant species (e.g., cows with intraruminal QA and RU application; Berger et al., 2012). These differences may be due to differences in gastrointestinal anatomy and physiology (Arts et al., 2004; Berger et al., 2012; Gohlke et al., 2013). Conversely, in newborn calves the forestomach system is just developing, thus newborn calves are functionally monogastrics (Drackley, 2008). The aim of the present study was to investigate the relative $\mathrm{BV}$ of quercetin after oral administration of $\mathrm{QA}$ or RU in calves during first month of life. We hypothesized that BV in calves depends on the form of application (QA and RU) and changes with age due to ontogenetic development and maturation of the gastrointestinal tract during first month of life. We further tested the hypothesis that quercetin application might affect metabolic and endocrine traits, especially concerning glucose metabolism in neonatal calves, because findings in literature pointed to impaired carbohydrate digestion and glucose absorption after flavonoid intake (Cermak et al., 2004; Tadera et al., 2006).

\section{MATERIALS AND METHODS}

\section{Animals and Feeding}

The experimental procedures were carried out according to the animal care guidelines and were approved by the relevant authorities of the State Mecklenburg-West Pomerania, Germany (LVL M-V/ TSD/7221.3-2.1-019/10). Twenty-one male German Holstein calves were examined on d 2 and 29 of life. All calves were spontaneously born from multiparous cows on neighboring farms and transported directly after birth to the experimental barn. Calves were kept in single boxes with straw bedding and had free access to water. Calves were fed twice daily (0700 and $1500 \mathrm{~h}$ ) with a nipple bottle or nipple bucket. On the first $3 \mathrm{~d}$ of life calves received pooled colostrum obtained from milkings 1,3 , and 5 (d 1, 2, and 3 after parturition, respectively; Table 1) at amounts of $8 \%$ of BW on d 1 and $10 \%$ of BW on d 2 and 3 (Steinhoff-Wagner et al., 2011). From d 4 until 29, calves received milk replacer (150 g/L; SalvaLac MiraPro 45, Salvana Tiernahrung GmbH, Klein-Offenseth Sparrieshoop, Germany) at $12 \%$ of $\mathrm{BW} / \mathrm{d}$ (Table 1). To ensure uptake of equal amounts of feed, refused amounts of colostrum or milk were tube-fed to calves. Milk intake was adapted to BW data once a week.

Colostrum or milk replacer was supplemented with chicken egg-derived immunoglobulins (Globigen Life Start 25\%, EW Nutrition GmbH, Visbek, Germany) composed of $75 \%$ dextrose and $25 \%$ whole egg powder (10.75\% CP, $10.50 \%$ crude fat, $0.10 \%$ crude fiber, and $2.50 \%$ ash), with high antibody titer against Escherichia coli type K 99, Salmonella Typhimurium and Salmonella Dublin, bovine rotavirus type G6 and G10, bovine coronavirus, Cryptosporidium parvum, and Clostridium perfringens serotype C. Immunoglobulins were added from d 2 to 6 . Respective amounts of immunoglobulins fed twice daily were 40, 32, 24, 16, and $8 \mathrm{~g} / \mathrm{d}$.

From d 4 on calves had free access to pelleted concentrate (Kälber Start 18/3 pell., Vollkraft Mischfutterwerke GmbH, Karstädt, Germany; Table 1) and hay. Concentrate intake was measured daily after morning milk feeding. To avoid iron deficiency, calves received $600 \mathrm{mg}$ of iron dextran subcutaneously (Ursoferran, Serumwerk Bernburg, Germany) on their first day of life. Navel disinfection was performed with $10 \%$ iodine solution (vet sept Lösung, Albrecht GmbH, Aulendorf, Germany) immediately after birth. Health status of calves was determined daily by measuring rectal temperature, heart rate, and respiratory rate, by evaluation of behavioral abnormalities, nasal discharge, respiratory sounds, fecal consistence, and by navel inspection.

\section{Treatment and Blood Sampling}

Calves were randomly assigned to 1 of 3 feeding groups ( $\mathrm{n}=7$ per group) receiving either no flavonoids (control group; CTRL), $9 \mathrm{mg}$ of $\mathrm{QA} / \mathrm{kg}$ of BW (quercetin aglycone dihydrate, Carl Roth GmbH, Karlsruhe, Germany), or $18 \mathrm{mg}$ of RU/kg of BW (rutin trihydrate, Carl Roth $\mathrm{GmbH}$ ), each resulting in a dose of $9 \mathrm{mg}$ of quercetin equivalents $(\mathbf{Q E}) / \mathrm{kg}$ of $\mathrm{BW}(30 \mu \mathrm{mol}$ of $\mathrm{QE} /$ $\mathrm{kg}$ of $\mathrm{BW}$ ) on $\mathrm{d} 2$ and 29 of life. Calves received the 
Table 1. Composition and amounts of colostrum, milk replacer, and concentrate fed to calves

\begin{tabular}{|c|c|c|c|c|c|}
\hline Item & $\begin{array}{c}\text { d } 1 \\
\text { colostrum } 1 \\
\text { milking } 1\end{array}$ & $\begin{array}{c}\mathrm{d} 2 \\
\text { colostrum } 1 \\
\text { milking } 3\end{array}$ & $\begin{array}{c}\text { d } 3 \\
\text { colostrum } 1 \\
\text { milking } 5\end{array}$ & \multicolumn{2}{|c|}{ d 4 to $30^{2}$} \\
\hline $\mathrm{DM}, \mathrm{g} / \mathrm{kg}$ & 206.9 & 154.7 & 139.3 & 110.0 & 880.0 \\
\hline Crude fat, $\mathrm{g} / \mathrm{kg}$ of DM & 169.2 & 240.5 & 274.9 & 190.9 & 43.0 \\
\hline Ash, $\mathrm{g} / \mathrm{kg}$ of $\mathrm{DM}$ & 48.3 & 55.6 & 56.0 & 73.6 & 74.0 \\
\hline Lactose, $\mathrm{g} / \mathrm{kg}$ of DM & 136.3 & 260.5 & 308.7 & 514.6 & - \\
\hline
\end{tabular}

${ }^{1}$ Colostrum was derived from multiparous cows and separately pooled from milkings 1,3 , and 5 after parturition, respectively.

${ }^{2}$ Hay was offered ad libitum except for days of bioavailability studies.

${ }^{3}$ Milk replacer (SalvaLac MiraPro 45, Salvana Tiernahrung GmbH, Klein-Offenseth Sparrieshoop, Germany), was composed of 45\% spray skim milk powder, $35 \%$ sweet whey powder, $18 \%$ plant oil (palm, coconut, and soy oil), $1.7 \%$ Lys, $0.8 \%$ Ca, $0.75 \%$ P, and added with 50,000 IU of vitamin A, 4,000 IU of vitamin $\mathrm{D}_{3}, 200 \mathrm{mg}$ of vitamin $\mathrm{E}$ ( $\alpha$-tocopherol acetate), $9 \mathrm{mg}$ of $\mathrm{Cu}$ (glycerine-copper chelate), citric acid, sorbic acid, butylhydroxytoluene (BHT), and $1.2 \times 10^{9}$ cfu of Enterococcus faecium E1706.

${ }^{4}$ Concentrate (Kälber Start 18/3, Vollkraft, Mischfutterwerke GmbH, Karstädt, Germany) was composed of wheat gluten, wheat bran, grain mash, sugar beet pulp, rapeseed meal, oat, rye, molasses, linseed, oat bran, soybean meal extract, calcium carbonate, sodium chloride, $0.6 \%$ phosphorous, $0.2 \%$ sodium, 10,800 IU of vitamin A, 1,215 IU of vitamin $\mathrm{D}_{3}, 30 \mathrm{mg}$ of vitamin E, $0.7 \mathrm{mg}$ of I, $0.4 \mathrm{mg}$ of Co, $54 \mathrm{mg}$ of $\mathrm{Mg}, 81$ $\mathrm{mg}$ of $\mathrm{Zn}$, and $0.4 \mathrm{mg}$ of Se per $\mathrm{kg}$ of DM.

whole dose of QA or RU during morning feeding, applying the QE suspension with a 10-mL syringe directly into the mouth.

The day before the study started, a catheter (Certofix Mono 340, Braun Melsungen AG, Melsungen, Germany) was inserted into the calves' right jugular vein and blood samples were taken before (time point 0 ), and $0.5,1,1.5,2,2.5,3,4,6,8,12,24$, and $48 \mathrm{~h}$ after feeding using S-Monovette tubes (Sarstedt AG \& Co., Nümbrecht, Germany) containing lithium heparin (16 IU $/ \mathrm{mL}$ of blood) for analysis of plasma flavonols. Additional blood samples, except at 1.5, 2.5, and 48 $\mathrm{h}$, were taken for measurement of plasma concentrations of total protein, albumin, glucose, NEFA, urea, and lactate using tubes containing sodium fluoride and $\mathrm{K}_{3}$ EDTA $(1.0 \mathrm{mg} / \mathrm{mL}$ fluoride and $1.2 \mathrm{mg} / \mathrm{mL}$ EDTA). Blood sampled into tubes containing dipotassium EDTA $(1.8 \mathrm{mg} / \mathrm{mL})$ was used for determination of insulin and cortisol plasma concentrations. Catheters were flushed with $10 \mathrm{~mL}$ of sodium chloride solution (0.9\% sodium chloride, Braun Melsungen AG) after each blood sampling. Blood was immediately put on ice, centrifuged for $20 \mathrm{~min}$ at $1,500 \times g$ at $4^{\circ} \mathrm{C}$, and plasma was stored at $-80^{\circ} \mathrm{C}$ for flavonol analyses, and at $-20^{\circ} \mathrm{C}$ for analyses of metabolites and hormones.

\section{Analytical Methods}

Flavonols were extracted from plasma as described by Egert et al. (2008) and concentrations of quercetin aglycone and its methylated (isorhamnetin, tamarixetin) and dehydroxylated (kaempferol) derivatives were analyzed by HPLC with fluorescence detection as previously described (Ader et al., 2000; Berger et al., 2012; Gohlke et al., 2013). Briefly, plasma samples were thawed in a $40^{\circ} \mathrm{C}$ water bath. Then $980 \mu \mathrm{L}$ of plasma was acidified with $130 \mu \mathrm{L}$ of acetic acid $(0.583$ mol/L), spiked with $20 \mu \mathrm{L}$ of methanolic rhamnetin solution (internal standard, $1 \mathrm{mg} / 20 \mathrm{~mL}$ in methanol; Rotichrom HPLC, Carl Roth GmbH), and treated with a mixture of $\beta$-glucuronidase and sulfatase (from Helix pomatia Type $\mathrm{H}-1$, with final activities of 7,300 and $130 \mathrm{U} / \mathrm{mL}$ for glucuronidase and sulfatase, respectively; Sigma-Aldrich Chemie GmbH, Dreieich, Germany) to cleave the ester bonds of glucuronides and sulfates. After incubation at $37^{\circ} \mathrm{C}$ for $1 \mathrm{~h}, 3 \mathrm{~mL}$ of acetone was added and the samples were centrifuged at $3,700 \times g$ for $45 \mathrm{~min}$ at $4^{\circ} \mathrm{C}$. The supernatant was evaporated until dry. Residues were resolved in $200 \mu \mathrm{L}$ of methanol, and after $15 \mathrm{~min}$ in an ultrasonic bath $77.5 \mu \mathrm{L}$ of nanopure water and $22.5 \mu \mathrm{L}$ of hydrochloric acid (10 $\mathrm{mol} / \mathrm{L}$ ) were added. For flavonol analyses by HPLC, 30 $\mu \mathrm{L}$ of the final solution was injected by a cooled $\left(4^{\circ} \mathrm{C}\right)$ autosampler (AS-2057 Plus, Jasco Deutschland GmbH, Groß-Umstadt, Germany) onto a C-18 Kromasil 100 column $(250 \times 4 \mathrm{~mm}$, particle size $=5 \mu \mathrm{m}$, Jasco Deutschland $\mathrm{GmbH}$ ) guarded by a precolumn (C-18 Inertsil ODS-2, $10 \times 4 \mathrm{~mm}$, particle size $=5 \mu \mathrm{m}$, Jasco Deutschland $\mathrm{GmbH}$ ). The eluent (flow rate: $1 \mathrm{~mL} / \mathrm{min}$ ) was composed of $0.025 \mathrm{~mol} / \mathrm{L}$ of sodium dihydrogen phosphate ( $\mathrm{pH} 2.4$ ), acetonitrile, and methanol (68:27:5 $\mathrm{vol} / \mathrm{vol} / \mathrm{vol}$ ). In a postcolumn reactor, the effluent was mixed with aluminum nitrate [flow rate $=0.4 \mathrm{~mL} / \mathrm{min}$, $1 \mathrm{mmol} / \mathrm{L}$ in methanol containing $7.5 \%$ (vol/vol) acetic acid] for derivatization, and fluorescence of the flavonolaluminum complex was measured using a fluorescence detector (excitation wavelength $=422 \mathrm{~nm}$, emission wavelength $=485 \mathrm{~nm}$; FP920, Jasco Deutschland $\mathrm{GmbH}$ ). Identification of peaks obtained was performed using the retention times of the standards, which were 
prepared with pure flavonols and treated in the same way as samples. The detection limit of flavonols was $\leq 10 \mathrm{nmol} / \mathrm{L}$ and the recovery rate was $92 \pm 2 \%$ (mean $\pm \mathrm{SE}$ ). Inter- and intraassay variances for quercetin were 7.2 and $0.5 \%$. The sum of plasma concentrations of quercetin and its metabolites in plasma is referred to as total flavonols.

Plasma metabolites were analyzed spectrophotometrically (ABX Penta 400; Horiba ABX SAS, Montpellier Cedex, France) by the Clinic for Cattle (University of Veterinary Medicine, Foundation, Hannover, Germany) using the respective kits: albumin (no. A11A01664) and lactate (no. A11A01721; Horiba Europe GmbH, Hannover, Germany), NEFA (no. 434-91795; Wako Chemicals GmbH, Neuss, Germany), glucose (no. 553-230) and total protein (no. 553-412; MTI Diagnostics GmbH, Idstein, Germany), and urea (no. LT-UR 0050; Labor + Technik E. Lehmann GmbH, Berlin, Germany).

Plasma insulin concentrations were determined using an RIA as previously described (Vicari et al., 2008). Plasma cortisol concentrations were analyzed using a commercial ELISA kit validated for bovine plasma (EIA-1887; DRG Instruments GmbH, Marburg, Germany; Weber et al., 2013). Cross reactivities of the monoclonal antibody against corticosterone and progesterone were 45 and $9 \%$, respectively, and to any further plasma steroids lower than $2 \%$. Test sensitivity was $3.4 \mathrm{ng} / \mathrm{mL}$; inter- and intraassay variations were 5.3 and $12.1 \%$, respectively.

Colostrum was analyzed for DM, CP, crude fat, and ash content (Qualitätsprüfungs- und Dienstleistungsgesellschaft Mecklenburg-Vorpommern mbH, Güstrow, Germany) according to the Weender standard procedure (Naumann and Bassler, 2004), as shown in Table 1. Chemical composition of milk replacer and concentrates were according to the manufacturers' declarations (Table 1).

\section{Calculations and Statistical Analyses}

Quercetin measurements were corrected by baseline concentration (first blood sample, before QA or RU administration), then area under the curve (AUC) was calculated for quercetin and its metabolites (isorhamnetin, tamarixetin, and kaempferol) according to the trapeziodale rule between 0 and $24 \mathrm{~h}$ using GraphPad Prism 3 (GraphPad Software Inc., San Diego, CA, version 3.03). For single quercetin metabolites, AUC proportion relative to AUC of total flavonols (sum of quercetin, isorhamnetin, tamarixetin, and kaempferol) was calculated in addition. Maximum plasma flavonol concentrations $\left(\mathbf{C}_{\max }\right)$ and time after intake until $\mathbf{C}_{\max }$ was reached $\left(\mathbf{T}_{\max }\right)$ were determined from individual plasma concentration-time curves. Relative BV of quercetin from RU was calculated as

$$
\text { Relative } \mathrm{BV}=\mathrm{AUC}_{\mathrm{RU}} / \mathrm{AUC}_{\mathrm{QA}} \times 100 \% \text {. }
$$

Statistical analyses were performed using SAS/STAT software (SAS Institute, 2010). All data are presented as $\mathrm{LSM} \pm \mathrm{SE}$. Body weight, concentrate intake, and pharmacokinetic parameters (AUC, $\mathrm{C}_{\max }, \mathrm{T}_{\max }$ ), as well as proportions of single metabolites on d 2 and 29, were analyzed by repeated measurement ANOVA using the Mixed procedure with group (levels: CTRL, QA, $\mathrm{RU}$; for proportional calculations only $\mathrm{QA}$ and RU), repeated variable day (levels: d 2, 29), and group $\times$ day interaction as fixed effects in the model. Repeated measures on each calf were taken into account by using the repeated statement of the Mixed procedure with an autoregressive residual covariance structure. Plasma concentration of total flavonols as well as metabolite and hormone data were analyzed by repeated measurement ANOVA using the Mixed procedure, as described previously, with group (levels: CTRL, QA, RU), day (levels: d 2, 29), time changes within d 2 and 29 (several time points before and after feed intake on $\mathrm{d} 2$ and 29, respectively), and respective interactions as fixed effects. Pairwise differences among treatments and time changes were tested by the Tukey-Kramer-test. Effects were considered significant if $P<0.05$.

\section{RESULTS}

\section{$B W$ and Feed Intake}

All calves were born spontaneously and healthy. Birth weight was $47.4 \pm 1.0 \mathrm{~kg}$. Body weight increased with time in all groups $(P<0.01)$ and was $65.5 \pm 1.3$ $\mathrm{kg}$ on d 29 without differences between groups. Milk intake was $3.8 \pm 0.1 \mathrm{~kg} / \mathrm{d}$ on d $1(8 \%$ of $\mathrm{BW}), 4.8 \pm$ $0.1 \mathrm{~kg} / \mathrm{d}$ on $\mathrm{d} 2(10 \%$ of BW), and $6.9 \pm 0.1 \mathrm{~kg}$ on d 29 . Concentrate intake was $1.59 \pm 0.28 \mathrm{~kg} /$ calf and increased equally with time $(P<0.01)$ in all groups. Average daily gain from birth to d 29 was $612 \pm 28 \mathrm{~g} / \mathrm{d}$ without group differences.

\section{BV Studies}

Plasma concentrations of total flavonols of CTRL were close to or below the detection limit on d 2 and 29, respectively (Figure 1A, B). In QA- and RU-fed calves, plasma concentrations of total flavonols increased $(P<$ $0.05)$ after flavonoid administration on $\mathrm{d} 2$ and returned to baseline concentrations $48 \mathrm{~h}$ after administration (Figure 1A). On d 2, plasma concentrations of total 
A

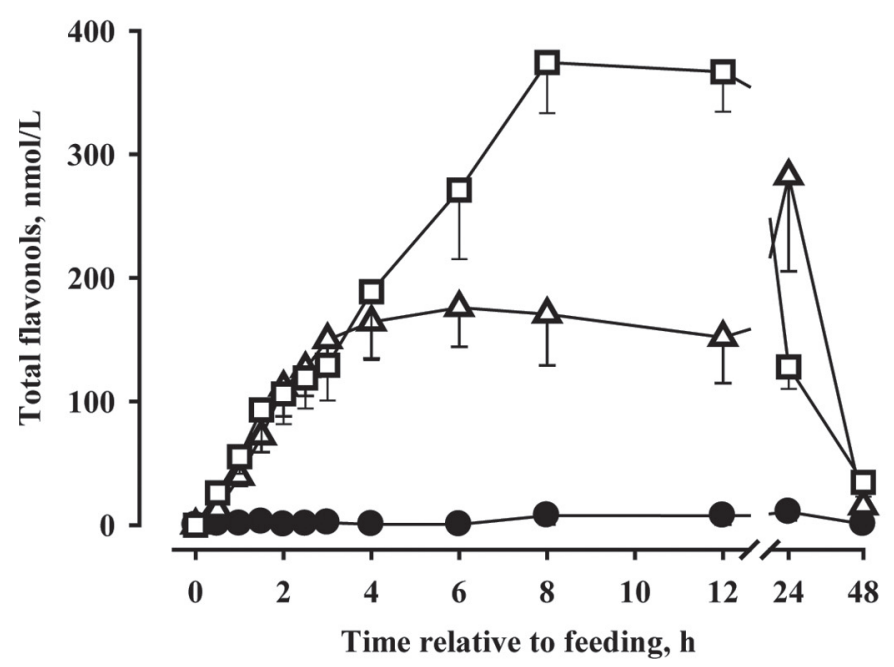

B

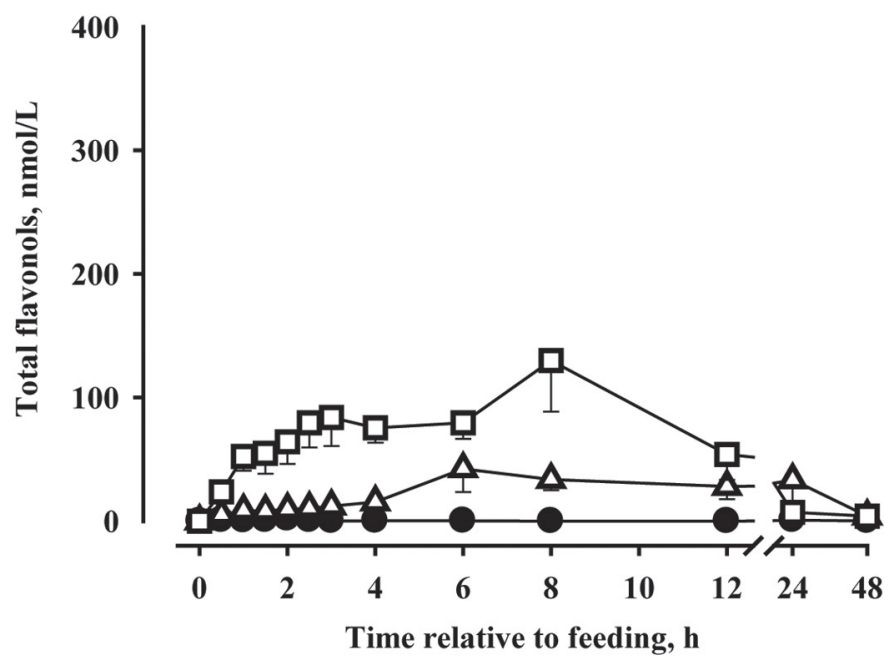

Figure 1. Plasma concentration-time-curves of total flavonols after oral administration of $9 \mathrm{mg}$ of quercetin $/ \mathrm{kg}$ of $\mathrm{BW} \times$ day as quercetin aglycone $(\square)$, rutin trihydrate $(\Delta)$, or no flavonoid $(\bullet)$ on d $2($ A) and 29 (B) of life. Values are LSM \pm SE; $\mathrm{n}=7$.

flavonols were greater at 8 and $12 \mathrm{~h}(P<0.01)$, but were smaller at $24 \mathrm{~h}$ after flavonoid administration $(P$ $<0.01)$ in QA- than in RU-fed calves.

On d 29, postprandial plasma concentrations of total flavonols increased far less distinctly $(P<0.01)$ when compared with d 2 (Figure 1A, B). Further, plasma concentrations of total flavonols increased until $8 \mathrm{~h}$ after administration $(P<0.01)$ in QA-, but not in RUfed calves (Figure 1B). Plasma concentrations of total flavonols on $\mathrm{d} 29$ tended to be greater $(P<0.1)$ in QA- than in RU-fed calves.

Compared with QA- (100\%), RU-fed calves showed a relative BV of quercetin of $72.5 \%$ on $\mathrm{d} 2$ and of $49.6 \%$ on d 29. On d 2, AUC of total flavonols, quercetin, and quercetin metabolites in QA- and RU-fed calves differed $(P<0.05)$ from CTRL, and were greater $(P$ $<0.001$ ) on d 2 than on 29 for both treatments (Table $2)$. On d 2, AUC of quercetin and isorhamnetin was greater $(P<0.05)$ and tended to be greater for total flavonols $(P<0.1)$, but was lower for tamarixetin $(P$ $<0.05)$ in QA- than in RU-fed calves. On d 29, AUC of quercetin was greater $(P<0.05)$ in $\mathrm{QA}$-fed calves than in CTRL.

On $\mathrm{d} 2, \mathrm{C}_{\max }$ of total flavonols, quercetin, and quercetin metabolites except kaempferol of QA- and RU-fed calves differed from CTRL $(P<0.05$; Table 2$)$, whereas on d 29 only $\mathrm{C}_{\max }$ of total flavonols and quercetin of QA-fed calves differed $(P<0.05)$ from CTRL. Maximal plasma concentrations of total flavonols, quercetin, and isorhamnetin decreased $(P<0.05)$ or tended to decrease (kaempferol, tamarixetin; $P<0.1$ ) in QA- and RU-fed calves from d 2 to 29 , respectively. On d 2, $\mathrm{C}_{\max }$ was greater $(P<0.05)$ for quercetin and isorhamnetin, but was lower for tamarixetin in QA- than in RU-fed calves.

Time to reach $\mathrm{C}_{\max }$ in $\mathrm{QA}$ - and $\mathrm{RU}$-fed calves was not affected by day, but indicated treatment effects for total flavonols, isorhamnetin, and tamarixetin (Table $2)$. For isorhamnetin, $\mathrm{T}_{\max }$ was greater $(P<0.05)$ in RU- than in QA-fed calves on both days.

Relative distribution of single flavonols (quercetin, isorhamnetin, tamarixetin, and kaempferol) proportionately to total flavonols in plasma showed highest values for quercetin on both days and in both groups (QA and RU). Proportion of single flavonols changed with time, namely increased for quercetin $(P<0.05)$ but decreased for isorhamnetin and tamarixetin $(P<$ 0.05 ) from d 2 to 29 (Figure 2A, B). On d 2, proportion of isorhamnetin was greater $(P<0.05)$ and proportion of tamarixetin was smaller $(P<0.05)$ in $\mathrm{QA}$ - than in RU-fed calves (Figure 2A).

\section{Plasma Concentrations of Metabolites and Hormones}

Plasma concentrations of total protein decreased $(P$ $<0.05)$ from d 2 to 29 in CTRL and were greater on d 2 in CTRL than in QA-fed calves $(P<0.05$; Table 3). Plasma concentrations of albumin increased $(P<$ 0.01 ) and plasma concentrations of lactate and urea decreased $(P<0.01)$ from d 2 to 29 without any group effect (Table 3). Mean glucose and NEFA plasma concentrations decreased $(P<0.05)$ from d 2 to 29 in all groups, but concentrations did not differ among groups 
Table 2. Pharmacokinetic parameters after oral administration of quercetin as quercetin aglycone (QA) or rutin trihydrate (RU) on d 2 and 29 of life; calves of the control group (CTRL) received no flavonoids

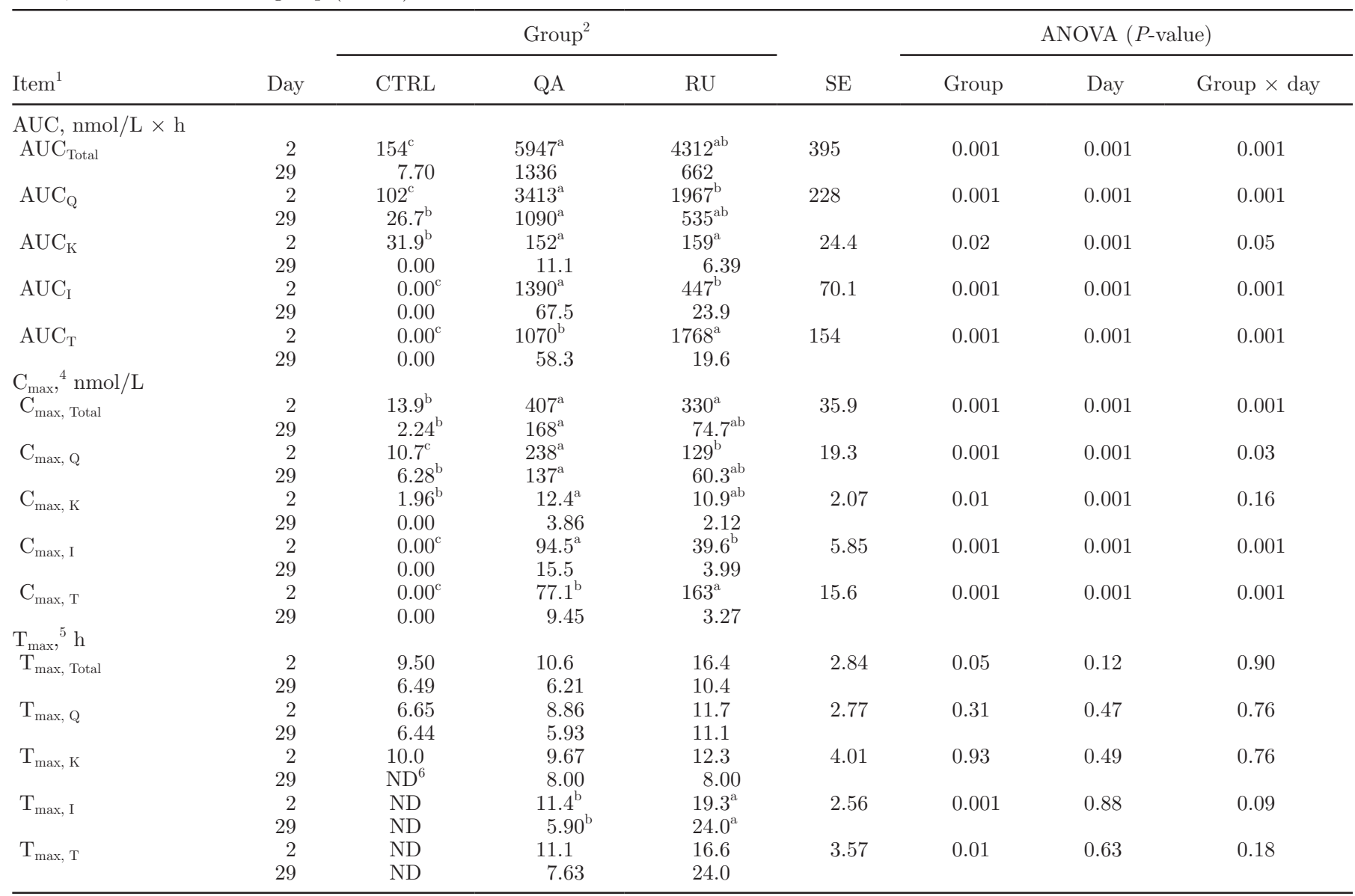

${ }^{\mathrm{a}-c} \mathrm{LSM}$ in a row with different superscripts differ $(P<0.05)$.

${ }^{1}$ Values are LSM with SE, $\mathrm{n}=7$ per group.

${ }^{2}$ Group: $\mathrm{QA}=30 \mu \mathrm{mol} /(\mathrm{kg}$ of $\mathrm{BW} \times \mathrm{d})$ quercetin aglycone; $\mathrm{RU}=30 \mu \mathrm{mol} /(\mathrm{kg}$ of $\mathrm{BW} \times \mathrm{d})$ rutin trihydrate; CTRL $=$ no flavonol fed

${ }^{3} \mathrm{AUC}=$ area under the plasma concentration-time curve of flavonols from 0 to $24 \mathrm{~h}$, calculated by subtracting baseline values (time point 0 ) from all other time points according to the trapezoidal rule; $\mathrm{AUC}_{\text {Total }}, \mathrm{AUC}_{\mathrm{Q}}, \mathrm{AUC}_{\mathrm{K}}, \mathrm{AUC}_{\mathrm{I}}, \mathrm{AUC}_{\mathrm{T}}=\mathrm{AUC}$ of total flavonols $(\mathrm{Total})$ or of the respective quercetin metabolites quercetin aglycone $(\mathrm{Q})$, kaempferol $(\mathrm{K})$, isorhamnetin $(\mathrm{I})$, and tamarixetin $(\mathrm{T})$, respectively.

${ }^{4} \mathrm{C}_{\max }=$ maximum plasma concentration of flavonols subtracted by basal plasma concentration before feed intake; $\mathrm{C}_{\max , \text { Total }}, \mathrm{C}_{\max , \mathrm{Q}}, \mathrm{C}_{\max , \mathrm{K}}, \mathrm{C}_{\max }$ ${ }_{\mathrm{I}}, \mathrm{C}_{\max , \mathrm{T}}=$ maximum plasma concentration of total flavonols (Total), quercetin aglycone (Q), kaempferol (K), isorhamnetin (I), and tamarixetin $(\mathrm{T})$, respectively.

${ }^{5} \mathrm{~T}_{\max }=$ time until $\mathrm{C}_{\max }$ was reached; $\mathrm{T}_{\max , \text { Total }}, \mathrm{T}_{\max , \mathrm{Q}}, \mathrm{T}_{\max , \mathrm{K}}, \mathrm{T}_{\max , \mathrm{I}}, \mathrm{T}_{\max , \mathrm{T}}=$ time until $\mathrm{C}_{\max , \text { Total }}, \mathrm{C}_{\max , \mathrm{Q}}, \mathrm{Cmax}_{\mathrm{K}}, \mathrm{C}_{\max , \mathrm{I}}, \mathrm{C}_{\max , \mathrm{T}}$ was reached, respectively.

${ }^{6} \mathrm{ND}=$ Not definable

(Table 3). Considering the day course of the plasma metabolites, plasma concentrations of glucose increased $(P$ $<0.01)$, whereas NEFA decreased $(P<0.01)$ after feed intake in all groups on d 2 and 29, respectively (Figure 3A-D). The increase of plasma insulin concentrations after feed intake was more pronounced $(P<0.05)$ on d 29 than on d 2, but without group effects (Figure 4A, B; Table 3). Plasma concentrations of cortisol decreased $(P<0.05)$ after feed intake on both days with mean concentrations being greater $(P<0.05)$ on $\mathrm{d} 2$ than on d 29 (Figure 4C, D; Table 3).

\section{DISCUSSION}

Without dietary supplementation of quercetin (CTRL group) plasma concentrations of total flavonols were close to or below the detection limit on $\mathrm{d}$ 2 and 29. However, small amounts of quercetin and its dehydroxylated metabolite kaempferol were found in blood plasma on d 2 and 29 in the control group. According to Besle et al. (2010), flavonoids are natural components of bovine milk and their concentration is affected by cow's diet. Although colostrum and milk 
A Day 2

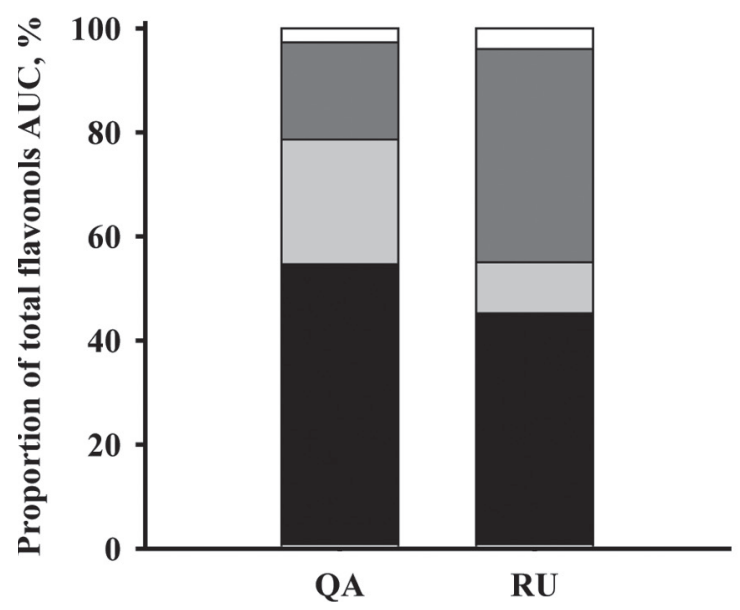

B

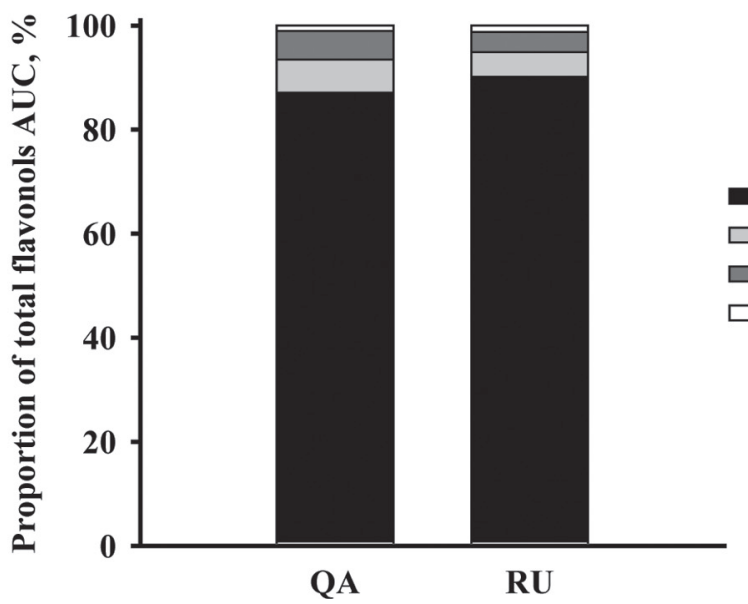

Day 29

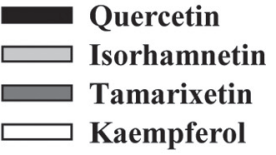

Figure 2. Proportion of single flavonols (quercetin, isorhamnetin, tamarixetin, and kaempferol) in plasma after oral administration of 9 mg of quercetin $/ \mathrm{kg}$ of BW $\times$ day as quercetin aglycone (QA) and rutin trihydrate $(\mathrm{RU})$ on $\mathrm{d} 2$ and 29 of life. Values are LSM \pm SE; $\mathrm{n}=7$.

replacer were not analyzed for flavonoid content in the present study, it can be assumed that colostrum is most likely the source for flavonoids found in CTRL calves at d 2. Apart from colostrum, feed components such as concentrates and hay may also contain flavonoids (Fraisse et al., 2007; Reynaud et al., 2010), which could explain measurable, albeit very low, plasma concentrations of quercetin and its metabolites at least in older calves (d 29).
In calves, quercetin was systemically available from both supplements, QA as well as RU. Interestingly, plasma values obtained for quercetin and its metabolites with an intact flavonol structure were greater on d 2 than on d 29, indicating better absorption or less excretion in younger animals. This may be explained by a different degree of gastrointestinal maturation and intestinal permeability on d 2 and 29, respectively (Blum, 2006). Thus, the epithelium in newborn animals

Table 3. Blood plasma concentrations of metabolites and hormones of calves after oral administration of quercetin as quercetin aglycone (QA), rutin trihydrate (RU), or no flavonoid (CTRL) on d 2 and d 29

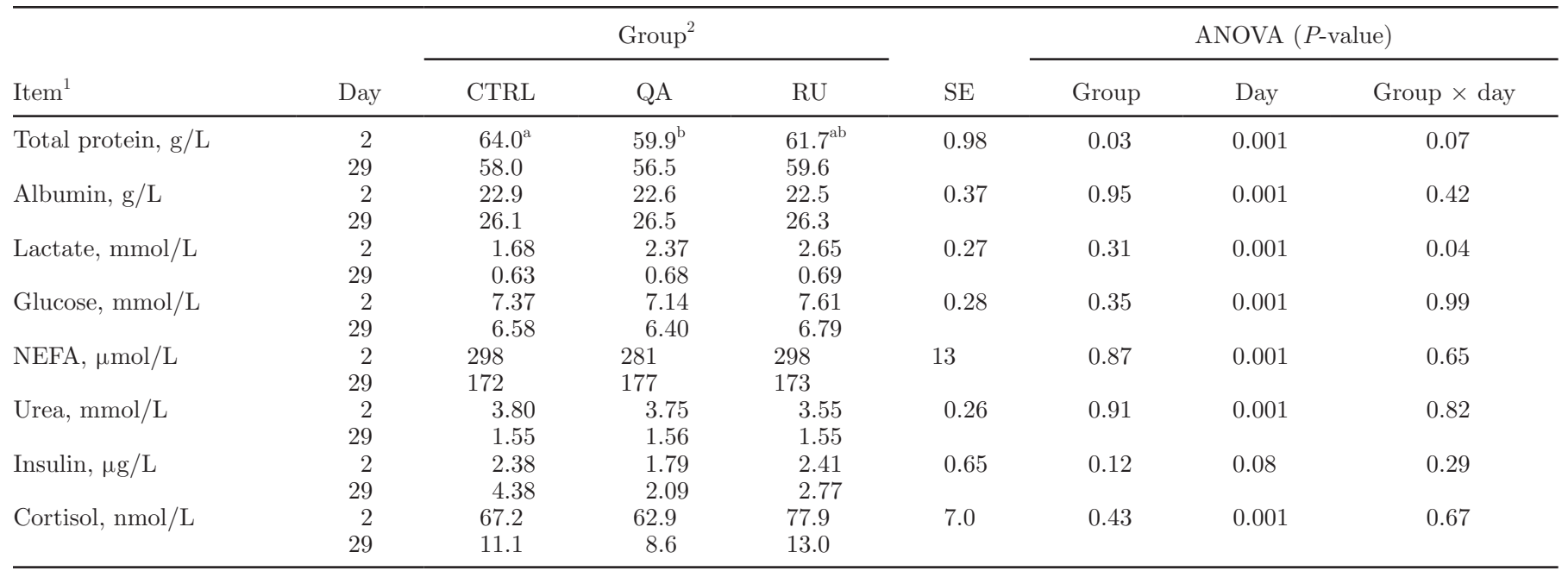

${ }^{\mathrm{a}, \mathrm{b}} \mathrm{LSM}$ in a row with different superscripts differ $(P<0.05)$.

${ }^{1}$ Values are LSM based on plasma concentrations in blood samples taken before and until $24 \mathrm{~h}$ after morning feeding on d 2 and 29 , respectively; $\mathrm{n}=7$ per group.

${ }^{2}$ Group: $\mathrm{QA}=30 \mu \mathrm{mol} /(\mathrm{kg}$ of $\mathrm{BW} \times \mathrm{d})$ quercetin aglycone; $\mathrm{RU}=30 \mu \mathrm{mol} /(\mathrm{kg}$ of $\mathrm{BW} \times \mathrm{d})$ rutin trihydrate; CTRL $=$ no flavonol fed. 
A

Day 2

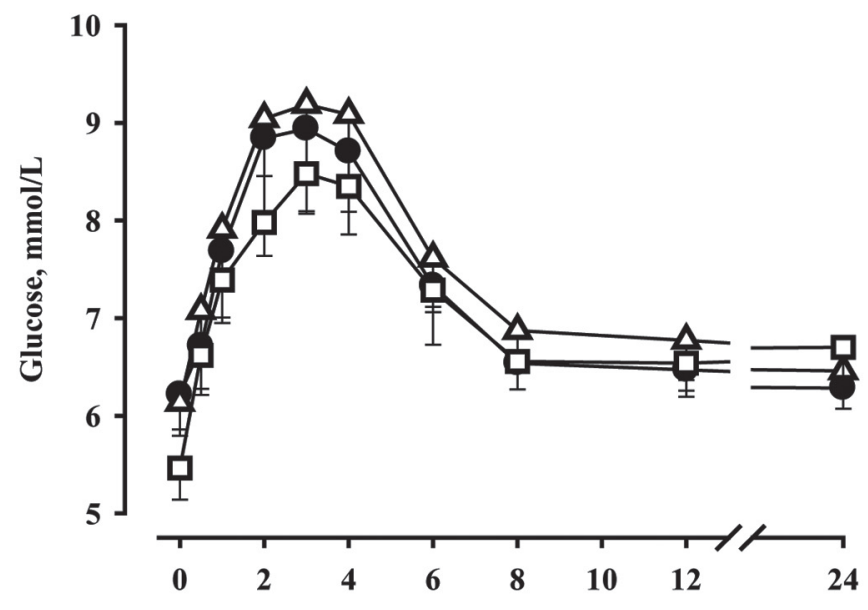

Time relative to feeding, $h$

C

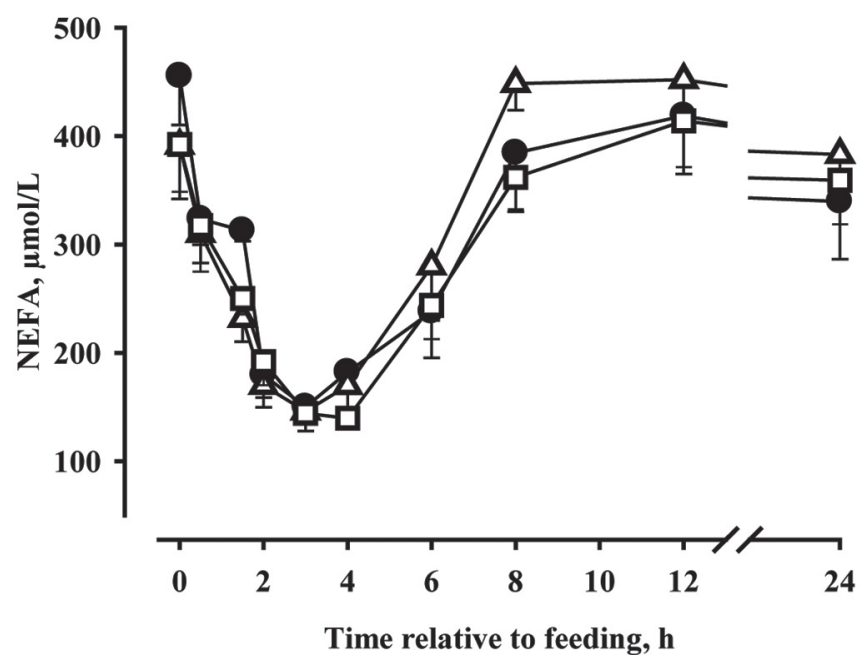

B

Day 29

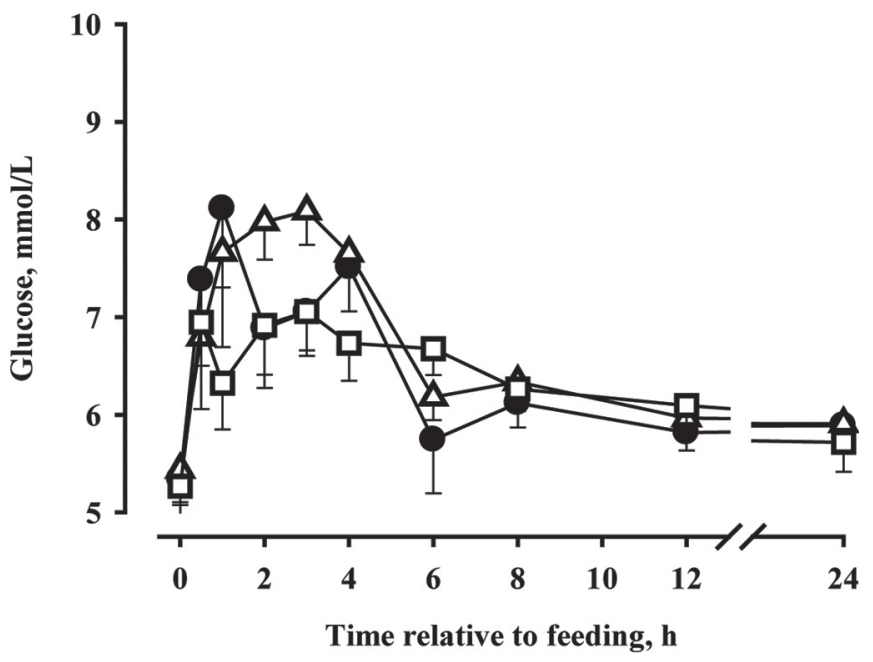

D

Day 29

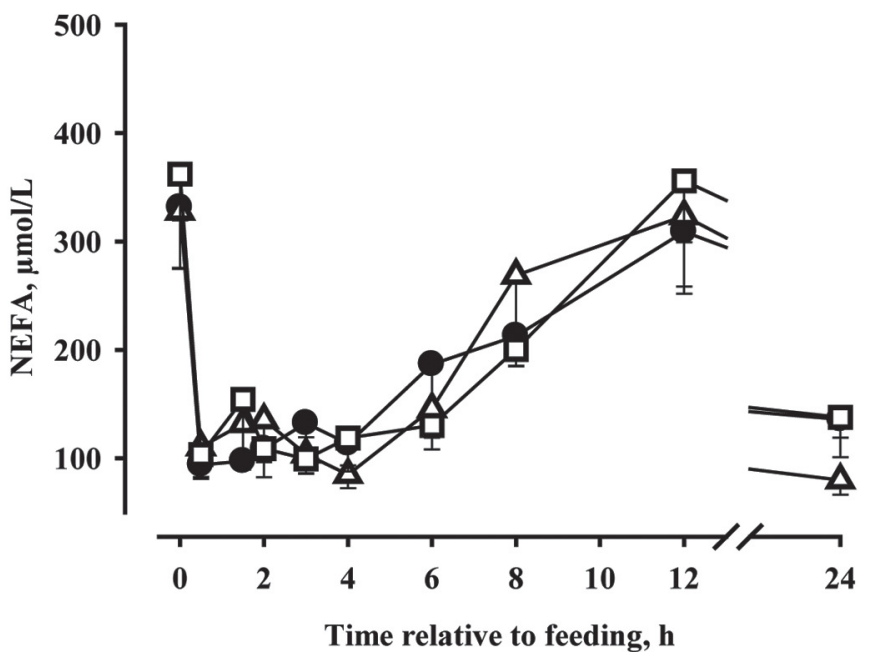

Figure 3. Plasma concentrations of glucose (A, B) and NEFA (C, D) after oral administration of $9 \mathrm{mg}$ of quercetin $/ \mathrm{kg}$ of BW $\times$ day as quercetin aglycone $(\square)$, rutin trihydrate $(\Delta)$, or no flavonoid $(\bullet)$ on d 2 and 29 of life. Values are LSM $\pm \mathrm{SE} ; \mathrm{n}=7$.

is characterized by vacuolated epithelial cells, which are not present in older animals (Bainter, 2002; Blum, 2006). This has possibly contributed to a greater absorption of quercetin from both sources (QA and RU) on d 2 compared with d 29 in calves. Furthermore, the reticulorumen and microbial activities might be already more developed in 29- than in 2-d-old calves, resulting in partial ruminal degradation of the flavonoids applied (Heinrichs and Jones, 2003; Guilloteau et al., 2009; Berger et al., 2012; Li et al., 2012). The $\mathrm{BV}$ of quercetin from both, QA and RU, especially on d 29 could probably be improved when encapsulated quercetin preparations will be used (Ding et al., 2014).
On both days investigated, feeding of QA resulted in greater plasma concentrations of total flavonols, quercetin, and its metabolites than feeding of RU, indicating QA as a better source of quercetin than RU with respect to the BV of quercetin. Markedly lower plasma concentrations of total flavonols were also seen in monogastric species after feeding of RU instead of QA at dosages comparable to the current study (Manach et al., 1997; Cermak et al., 2003; Reinboth et al., 2010). Thus, the present results obtained in calves are in principal accordance with studies on the BV of quercetin in monogastric species, such as rats (Manach et al., 1997), dogs (Reinboth et al., 2010), pigs (Cermak et al., 2003; 
A

Day 2

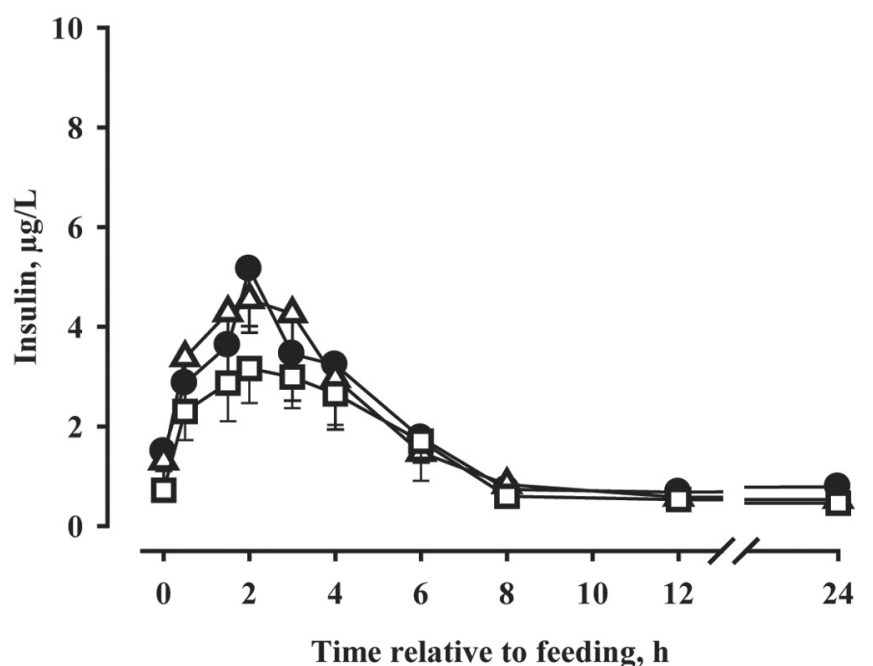

C

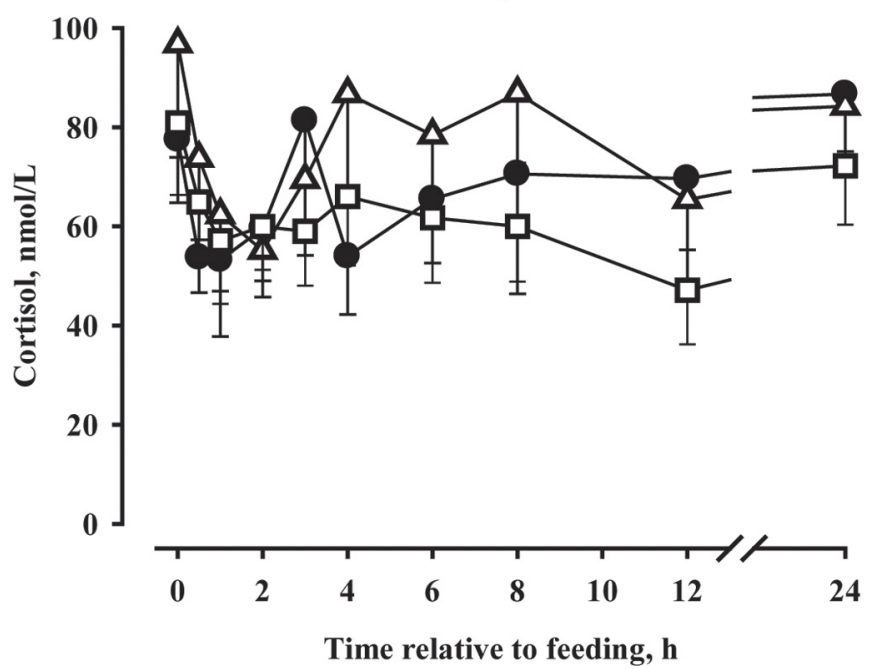

B

Day 29

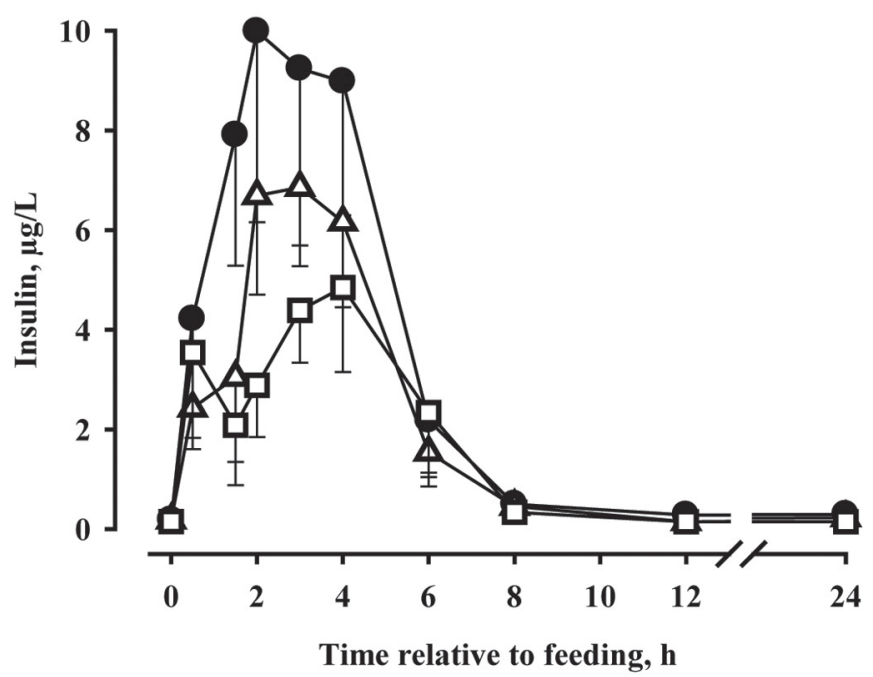

D

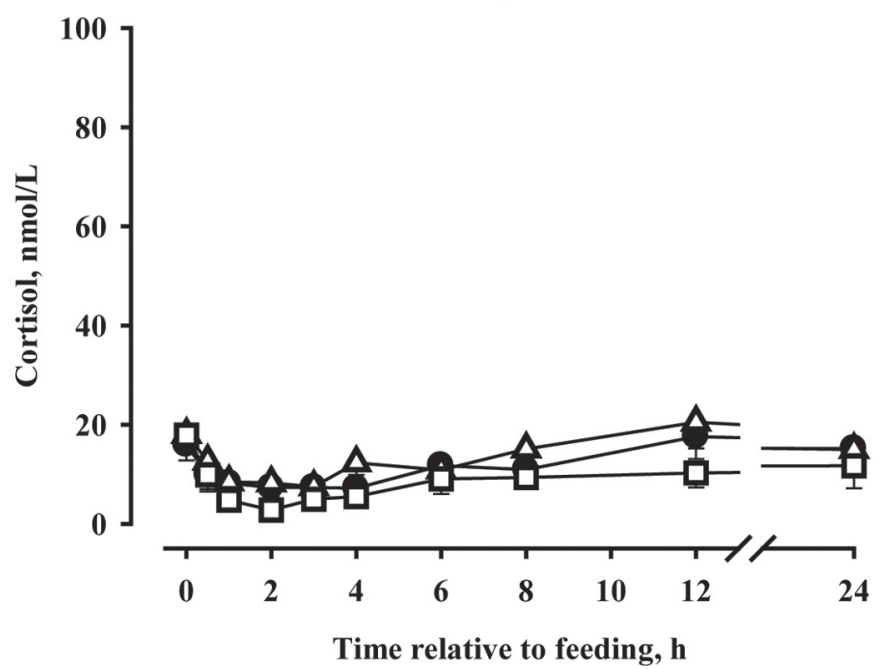

Figure 4. Plasma concentrations of insulin $(\mathrm{A}, \mathrm{B})$ and cortisol $(\mathrm{C}, \mathrm{D})$ after oral administration of $9 \mathrm{mg}$ of quercetin $/ \mathrm{kg}$ of BW $\times$ day as quercetin aglycone $(\square)$, rutin trihydrate $(\triangle)$, or no flavonoid $(\bullet)$ on d 2 and 29 of life. Values are LSM $\pm \mathrm{SE} ; \mathrm{n}=7$.

Lesser et al., 2004), and humans (Erlund et al., 2000; Egert et al., 2008). As the newborn calf is considered as a functionally monogastric animal (Drackley, 2008), these findings are not surprising.

Concerning RU application, studies in monogastric species often indicate a delayed increase of quercetin and its metabolites in blood plasma (Erlund et al., 2000; Cermak et al., 2003; Reinboth et al., 2010). In the present study, maximal plasma concentrations of quercetin and its metabolites were measured much later after RU than after QA feeding, indicating different intestinal sites for absorption (Erlund et al., 2000). In RU-fed calves, quercetin and its metabolites, at least on $\mathrm{d} 2$, most likely derive from absorption in both the small and the large intestine. In addition, we found the same slow increase of quercetin and its metabolites in blood plasma after QA and RU feeding, but the increase stopped much earlier in RU- than in QA-fed calves. In general, the sugar moiety in flavonol molecules determines the absorption of flavonoids in organisms (Day et al., 1998; Hollman et al., 1999) and QA is supposed to already be absorbed in the small intestine. More complex glycosides, such as the glucorhamnoside RU, are absorbed in distal parts of the small intestine or in the colon of monogastric animals, where flavonol molecules are hydrolyzed by microorganisms. 
Thus, the lack of rhamnosidase activity in the small intestine can be considered as one reason for delayed and lower absorption of RU than of QA (Erlund et al., 2000; Cermak et al., 2003). Our pattern of relative BV of total flavonols after RU feeding fits to relative BV of total flavonols in blood plasma after duodenal, but not after ruminal application in dairy cows (Berger et al., 2012; Gohlke et al., 2013), indicating a low ruminal function in our calves during first month of life.

Interestingly, pharmacokinetics of quercetin absorption after QA feeding markedly differed between calves and adult cattle (Berger et al., 2012; Gohlke et al., 2013) or monogastric animals (Erlund et al., 2000; Cermak et al., 2003; Reinboth et al., 2010). The typical peak of total flavonol plasma concentrations some minutes after QA administration was not seen in newborn calves. As a consequence, time for reaching $\mathrm{C}_{\max }$ was much greater in calves than in adult ruminants and monogastrics. Comparable slow increases of quercetin and its metabolites as in newborn calves' blood plasma were only seen in rats (Manach et al., 1997). These differences in pharmacokinetics after QA feeding are difficult to explain, but a probable reason is the low release of milk protein into the duodenum due to abomasal casein clotting (Heinrichs and Jones, 2003; Guilloteau et al., 2009) and the potential binding of flavonoids to milk proteins (Gugler et al. 1975; Boulton et al., 1998; Janisch et al., 2004).

All measured metabolites and hormones were in physiological ranges and most of these findings were in accordance with previous results indicating postnatal growth, especially protein accretion, and development in breeding as well as suckling calves (Egli and Blum, 1998; Nussbaum et al., 2002; Schiessler et al., 2002). Conversely, except for total protein concentrations on d 2, we found no treatment effects by QA or RU feeding in these calves. Plasma protein concentrations were lower in QA-fed than in CTRL calves, a finding that was hard to explain because all calves received the same pooled colostrum with identical IgG content at first days of life. Postprandial changes of metabolites and hormones have been reported previously (Hadorn et al., 1997; Hammon and Blum, 1998), but systemic glucose metabolism was not affected by QA or RU feeding, as we have assumed from findings in literature (Cermak et al., 2004; Tadera et al., 2006).

In conclusion, BV of quercetin and its metabolites in newborn calves is more pronounced when quercetin is fed as QA than as RU. These findings go along with data on $\mathrm{BV}$ of quercetin in lactating cows with duodenal application (Gohlke et al., 2013) and in monogastric species such as rats, dogs, and pigs (Manach et al., 1997; Cermak et al., 2003; Reinboth et al., 2010). Greater BV of quercetin on d 2 than on d 29 of life was probably due to reduced maturation status of the gastrointestinal tract in 2-d-old calves. However, effects of quercetin feeding on the antioxidative status should be investigated to validate health-protecting effects of quercetin feeding in neonatal calves.

\section{ACKNOWLEDGMENTS}

We gratefully thank Petra Schulz and Maike Gosse (Christian Albrechts University, Kiel, Germany) for excellent laboratory assistance as well as Annette Zeyner, Kirsten Büsing (University of Rostock, Rostock, Germany), and Bernd Stabenow (FBN Dummerstorf, Dummerstorf, Germany) for providing experimental facilities. Chicken-egg derived immunoglobulins (Globigen Life Start 25\%) were generously provided by EW Nutrition GmbH (Visbek, Germany). This work is part of the joint research project Food Chain Plus (FoCus) and was financially supported by the Federal Ministry of Education and Research, Bonn, Germany (BMFT grant no. 0315538B).

\section{REFERENCES}

Ader, P., A. Wessmann, and S. Wolffram. 2000. Bioavailability and metabolism of the flavonol quercetin in the pig. Free Radic. Biol. Med. 28:1056-1067. http://dx.doi.org/10.1016/S08915849(00)00195-7.

Arts, I. C. W., A. L. A. Sesink, M. Faassen-Peters, and P. C. H. Hollman. 2004. The type of sugar moiety is a major determinant of the small intestinal uptake and subsequent biliary excretion of dietary quercetin glycosides. Br. J. Nutr. 91:841-847. http:// dx.doi.org/10.1079/BJN20041123.

Bainter, K. 2002. Vacuolation in the young. Pages 55-110 in Biology of the Intestine in Growing Animals. R. Zabielski, P. C. Gregory, and B. Westrom, ed. Elsevier, Amsterdam, the Netherlands.

Berger, L. M., S. Wein, R. Blank, C. C. Metges, and S. Wolffram. 2012. Bioavailability of the flavonol quercetin in cows after intraruminal application of quercetin aglycone and rutin. J. Dairy Sci. 95:5047-5055. http://dx.doi.org/10.3168/jds.2012-5439.

Besle, J. M., D. Viala, B. Martin, P. Pradel, B. Meunier, J. L. Berdagué, D. Fraisse, J. L. Lamaison, and J. B. Coulon. 2010. Ultraviolet-absorbing compounds in milk are related to forage polyphenols. J. Dairy Sci. 93:2846-2856. http://dx.doi.org/10.3168/jds.20092939.

Bhagwat, S., D. B. Haytowitz, and J. M. Holden. 2013. USDA Database for the Flavonoid Content of Selected Foods. Release 3.1. USDA, Agricultural Research Service. Accessed Apr. 15, 2014. http://www.ars.usda.gov/SP2UserFiles/Place/12354500/Data/ Flav/Flav3-1.pdf

Blum, J. W. 2006. Nutritional physiology of neonatal calves. J. Anim. Physiol. Anim. Nutr. (Berl.) 90:1-11. http://dx.doi.org/10.1111/ j.1439-0396.2005.00614.x.

Boulton, D. W., U. K. Walle, and T. Walle. 1998. Extensive binding of the bioflavonoid quercetin to human plasma proteins. J. Pharm. Pharmacol. 50:243-249. http://dx.doi. org/10.1111/j.2042-7158.1998.tb06183.x.

Cermak, R., S. Landgraf, and S. Wolffram. 2003. The bioavailability of quercetin in pigs depends on the glycoside moiety and on dietary factors. J. Nutr. 133:2802-2807.

Cermak, R., S. Landgraf, and S. Wolffram. 2004. Quercetin glucosides inhibit glucose uptake into brush-border-membrane vesicles of porcine jejunum. Br. J. Nutr. 91:849-855. http://dx.doi. org/10.1079/BJN20041128. 
Chase, C. C., D. J. Hurley, and A. J. Reber. 2008. Neonatal immune development in the calf and its impact on vaccine response. Vet. Clin. North Am. Food Anim. Pract. 24:87-104.

Day, A. J., M. S. DuPont, S. Ridley, M. Rhodes, M. J. Rhodes, M. R. Morgan, and G. Williamson. 1998. Deglycosylation of flavonoid and isoflavonoid glycosides by human small intestine and liver beta-glucosidase activity. FEBS Lett. 436:71-75. http://dx.doi. org/10.1016/S0014-5793(98)01101-6.

Ding, B., P. Chen, Y. Kong, Y. Zhai, X. Pang, J. Dou, and G. Zhai. 2014. Preparation and evaluation of folate-modified lipid nanocapsules for quercetin delivery. J. Drug Target. 22:67-75.

Drackley, J. K. 2008. Calf nutrition from birth to breeding. Vet. Clin. North Am. Food Anim. Pract. 24:55-86. http://dx.doi. org/10.1016/j.cvfa.2008.01.001

Egert, S., S. Wolffram, A. Bosy-Westphal, C. Boesch-Saadatmandi, A. E. Wagner, J. Frank, G. Rimbach, and M. J. Mueller. 2008. Daily quercetin supplementation dose-dependently increases plasma quercetin concentrations in healthy humans. J. Nutr. 138:16151621

Egli, C. P., and J. W. Blum. 1998. Clinical, haematological, metabolic and endocrine traits during the first three months of life of suckling simmentaler calves held in a cow-calf operation. Zentralbl Veterinarmed A 45:99-118.

Erlund, I., T. Kosonen, G. Alfthan, J. Mäenpää, K. Perttunen, J. Kenraali, J. Parantainen, and A. Aro. 2000. Pharmacokinetics of quercetin from quercetin aglycone and rutin in healthy volunteers. Eur. J. Clin. Pharmacol. 56:545-553. http://dx.doi.org/10.1007/ s002280000197.

Fraisse, D., A. Carnat, D. Viala, P. Pradel, J.-M. Besle, J.-B. Coulon, C. Felgines, and J.-L. Lamaison. 2007. Polyphenolic composition of a permanent pasture: Variations related to the period of harvesting. J. Sci. Food Agric. 87:2427-2435. http://dx.doi. org/10.1002/jsfa.2918.

Gaál, T., R. Ribiczeyne-Szabo, K. Stadler, J. Jakus, J. Reiczigel, P. Kover, M. Mezes, and L. Sumeghy. 2006. Free radicals, lipid peroxidation and antioxidant system in the blood of cows and newborn calves around calving. Comp. Biochem. Physiol. B Biochem. Mol. Biol. 143:391-396.

Gasparin, F. R. S., C. L. Salgueiro-Pagadigorria, L. Bracht, E. L. IshiiIwamoto, A. Bracht, and J. Constantin. 2003. Action of quercetin on glycogen catabolism in the rat liver. Xenobiotica 33:587-602. http://dx.doi.org/10.1080/0049825031000089100.

Godden, S. 2008. Colostrum management for dairy calves. Vet. Clin. North Am. Food Anim. Pract. 24:19-39.

Gohlke, A., C. J. Ingelmann, G. Nürnberg, A. Starke, S. Wolffram, and C. C. Metges. 2013. Bioavailability of quercetin from its aglycone and its glucorhamnoside rutin in lactating dairy cows after intraduodenal administration. J. Dairy Sci. 96:2303-2313. http:// dx.doi.org/10.3168/jds.2012-6234.

Gugler, R., M. Leschik, and H. J. Dengler. 1975. Disposition of quercetin in man after single oral and intravenous doses. Eur. J. Clin. Pharmacol. 9:229-234.

Guilloteau, P., R. Zabielski, and J. W. Blum. 2009. Gastrointestinal tract and digestion in the young ruminant: Ontogenesis, adaptations, consequences and manipulations. J. Physiol. Pharmacol. 60(Suppl. 3):37-46.

Hadorn, U., H. Hammon, R. M. Bruckmaier, and J. W. Blum. 1997. Delaying colostrum intake by one day has important effects on metabolic traits and on gastrointestinal and metabolic hormones in neonatal calves. J. Nutr. 127:2011-2023.

Hammon, H. M., and J. W. Blum. 1998. Metabolic and endocrine traits of neonatal calves are influenced by feeding colostrum for different durations or only milk replacer. J. Nutr. 128:624-632.

Hammon, H. M., J. Steinhoff-Wagner, U. Schönhusen, C. C. Metges, and J. W. Blum. 2012. Energy metabolism in the newborn farm animal with emphasis on the calf: Endocrine changes and responses to milk-born and systemic hormones. Domest. Anim. Endocrinol. 43:171-185.

Heinrichs, A. J., and C. M. Jones. 2003. Feeding the Newborn Calf. College of Agricultural Sciences, Agricultural Research, and Coop- erative Extension, Pennsylvania State University, University Park, PA.

Hertog, M. G. L., P. C. H. Hollman, and M. B. Katan. 1992. Content of potentially anticarcinogenic flavonoids of 28 vegetables and 9 fruits commonly consumed in the Netherlands. Proc. Nutr. Soc. 40:2379-2383. http://dx.doi.org/10.1021/jf00024a011.

Hollman, P. C. H., M. N. C. P. Bijsman, Y. van Gameren, E. P. J. Cnossen, J. H. M. de Vries, and M. B. Katan. 1999. The sugar moiety is a major determinant of the absorption of dietary flavonoid glycosides in man. Free Radic. Res. 31:569-573. http://dx.doi. org/10.1080/10715769900301141.

Inanami, O., A. Shiga, K. J. Okada, R. Sato, Y. Miyake, and M. Kuwabara. 1999. Lipid peroxides and antioxidants in serum of neonatal calves. Am. J. Vet. Res. 60:452-457.

Janisch, K. M., G. Williamson, P. Needs, and G. W. Plumb. 2004 Properties of quercetin conjugates: Modulation of LDL oxidation and binding to human serum albumin. Free Radic. Res. 38:877884. http://dx.doi.org/10.1080/10715760410001728415.

Kobayashi, Y., M. Miyazawa, A. Kamei, K. Abe, and T. Kojima. 2010. Ameliorative effects of mulberry (Morus alba L.) leaves on hyperlipidemia in rats fed a high-fat diet: Induction of fatty acid oxidation, inhibition of lipogenesis, and suppression of oxidative stress. Biosci. Biotechnol. Biochem. 74:2385-2395.

Lesser, S., R. Cermak, and S. Wolffram. 2004. Bioavailability of quercetin in pigs is influenced by the dietary fat content. J. Nutr. 134:1508-1511.

Li, R. W., E. E. Connor, C. Li, R. L. Baldwin VI, and M. E. Sparks. 2012. Characterization of the rumen microbiota of pre-ruminant calves using metagenomic tools. Environ. Microbiol. 14:129-139. http://dx.doi.org/10.1111/j.1462-2920.2011.02543.x.

Lindmark-Månsson, H., and B. Åkesson. 2000. Antioxidative factors in milk. Br. J. Nutr. 84:S103-S110.

Manach, C., C. Morand, C. Demigné, O. Texier, F. Régérat, and C Rémésy. 1997. Bioavailability of rutin and quercetin in rats. FEBS Lett. 409:12-16. http://dx.doi.org/10.1016/S0014-5793(97)004675.

Manach, C., A. Scalbert, C. Morand, C. Rémésy, and L. Jiménez. 2004. Polyphenols: Food sources and bioavailability. Am. J. Clin. Nutr. 79:727-747.

McGuirk, S. M. 2008. Disease management of dairy calves and heifers. Vet. Clin. North Am. Food Anim. Pract. 24:139-153.

Mee, J. F. 2008. Newborn dairy calf management. Vet. Clin. North Am. Food Anim. Pract. 24:1-17.

Middleton, E., C. Kandaswami, and T. C. Theoharides. 2000. The effects of plant flavonoids on mammalian cells: Implications for inflammation, heart disease, and cancer. Pharmacol. Rev. 52:673751.

Naumann, C., and R. Bassler. 2004. Die chemische Untersuchung von Futtermitteln. VDLUFA-Verlag, Darmstadt, Germany.

Nijveldt, R. J., E. van Nood, D. E. C. van Hoorn, P. G. Boelens, K van Norren, and P. A. M. van Leeuwen. 2001. Flavonoids: A review of probable mechanisms of action and potential applications. Am. J. Clin. Nutr. 74:418-425.

Nussbaum, A., G. Schiessler, H. M. Hammon, and J. W. Blum. 2002 Growth performance and metabolic and endocrine traits in calves pair-fed by bucket or by automate starting in the neonatal period. J. Anim. Sci. 80:1545-1555.

Quigley, J. D. III, and J. J. Drewry. 1998. Nutrient and immunity transfer from cow to calf pre- and postcalving. J. Dairy Sci. $81: 2779-2790$

Reinboth, M., S. Wolffram, G. Abraham, F. R. Ungemach, and R. Cermak. 2010. Oral bioavailability of quercetin from different quercetin glycosides in dogs. Br. J. Nutr. 104:198-203. http:// dx.doi.org/10.1017/S000711451000053X.

Reynaud, A., D. Fraisse, A. Cornu, A. Farruggia, E. Pujos-Guillot, J.-M. Besle, B. Martin, J.-L. Lamaison, D. Paquet, M. Doreau, and B. Graulet. 2010. Variation in content and composition of phenolic compounds in permanent pastures according to botanical variation. J. Agric. Food Chem. 58:5485-5494. http://dx.doi. org/10.1021/jf1000293. 
SAS Institute. 2010. SAS/QC 9.2: User's Guide, Second Edition. Cary, NC: SAS Institute Inc.

Schiessler, G., A. Nussbaum, H. M. Hammon, and J. W. Blum. 2002. Calves sucking colostrum and milk from their dams or from an automatic feeding station starting in the neonatal period: Metabolic and endocrine traits and growth performance. Anim. Sci. 74:431-444.

Steinhoff-Wagner, J., S. Görs, P. Junghans, R. M. Bruckmaier, E. Kanitz, C. C. Metges, and H. M. Hammon. 2011. Maturation of endogenous glucose production in preterm and term calves. J. Dairy Sci. 94:5111-5123. http://dx.doi.org/10.3168/jds.20114355.

Tadera, K., Y. Minami, K. Takamatsu, and T. Matsuoka. 2006. Inhibition of alpha-glucosidase and alpha-amylase by flavonoids. J. Nutr. Sci. Vitaminol. (Tokyo) 52:149-153.

Uetake, K. 2013. Newborn calf welfare: A review focusing on mortality rates. Anim. Sci. J. 84:101-105.
Vicari, T., J. J. G. C. van den Borne, W. J. J. Gerrits, Y. Zbinden, and J. W. Blum. 2008. Postprandial blood hormone and metabolite concentrations influenced by feeding frequency and feeding level in veal calves. Domest. Anim. Endocrinol. 34:74-88. http://dx.doi. org/10.1016/j.domaniend.2006.11.002.

Weber, C., C. Hametner, A. Tuchscherer, B. Losand, E. Kanitz, W. Otten, S. P. Singh, R. M. Bruckmaier, F. Becker, W. Kanitz, and H. M. Hammon. 2013. Variation in fat mobilization during early lactation differently affects feed intake, body condition, and lipid and glucose metabolism in high-yielding dairy cows. J. Dairy Sci. 96:165-180. http://dx.doi.org/10.3168/jds.2012-5574.

Williams, R. J., J. P. Spencer, and C. Rice-Evans. 2004. Flavonoids: Antioxidants or signalling molecules? Free Radic. Biol. Med. $36: 838-849$ 